\title{
The Shape Memory Polymeric Materials and the Additive Manufacturing Technology as Promoter of the Future Smart Society ${ }^{\dagger}$
}

\author{
Doina Dimonie * and Beatrice Girbaciu \\ INCDCP-ICECHIM Bucharest, 202 Spl. Independentei, 6th sector, 060021 Bucharest, Romania; \\ abgirbaciu@gmail.com \\ * Correspondence: ddimonie@icechim.ro \\ + Presented at the 15th International Symposium "Priorities of Chemistry for a Sustainable Development" \\ PRIOCHEM, Bucharest, Romania, 30th October-1st November 2019.
}

Published: 12 October 2019

Keywords: synthesis; benzimidazole; DFT; NLO properties; hyperpolarizability ( $\beta$ )

Humans have progressed from the Stone Age, through the Bronze, Iron, and Steel Ages, into its current age, the Age of Polymers, which will be the material of choice [1]. Considering the National Institute for Reasearch and Development in Chemistry and Petrochemistry's (ICECHIM) strategy, for the next decade, in the field of polymeric materials, the roll-up will present, in three parts, the role of the shape memory polymeric materials in the development of the future smart society, in correlation with the additive manufacturing technology that is on the verge of industrialization [2].

The first part of the roll-up will present the ICECHIM strategy regarding the research on structurated polymeric materials by classical, active, and intelligent types, which can be applied via classical technology or emerging technologies (3D and 4D printing)-Figure 1 . The second part of the roll-up will present an overview of the two emerging technologies (3D and 4D printing) and their future evolution. The third part will be dedicated to the shape memory polymeric materials and their importance in the future development of society. They are the materials that respond to external stimuli by changing their shape and/or volume and/or color and/or physical properties-Figure 2 (e.g., glass transition temperature, deformation recovery speed, Young's modulus, stiffness -indicator of the tendency of an element to return to its original form, etc.)

ICECHIM has already begun the pursuit of achieving shape memory polymeric materials, the current state of the research being at the laboratory stage.
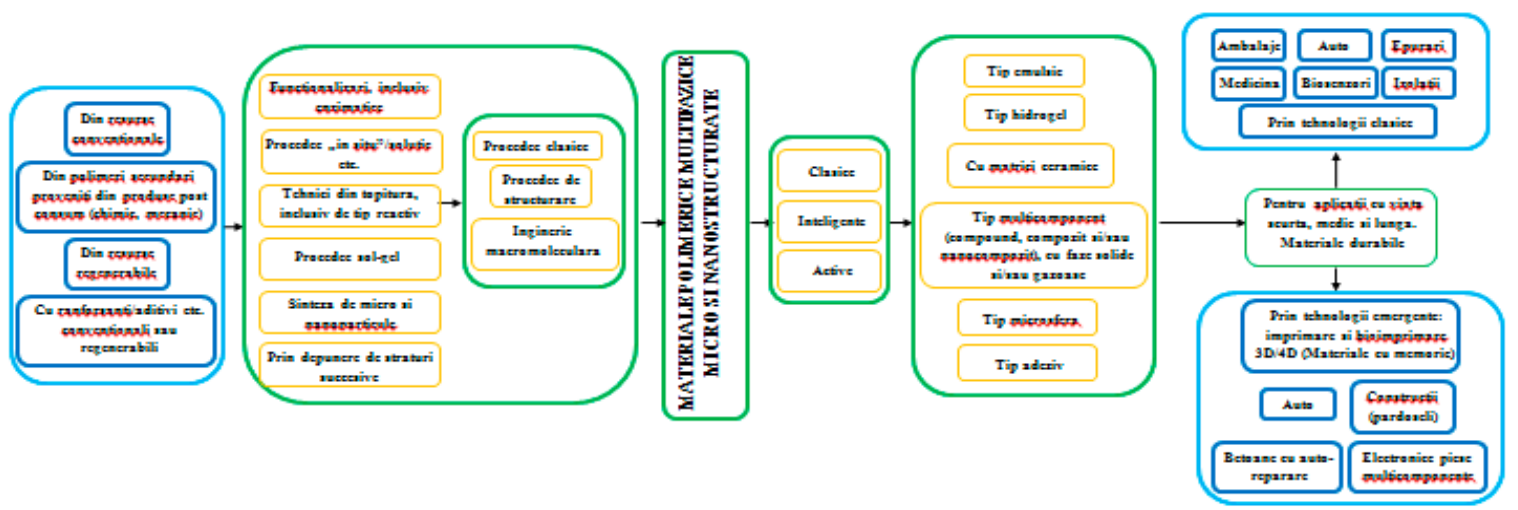

Figure 1. The ICECHIM strategy in the advanced polymeric materials domain. 


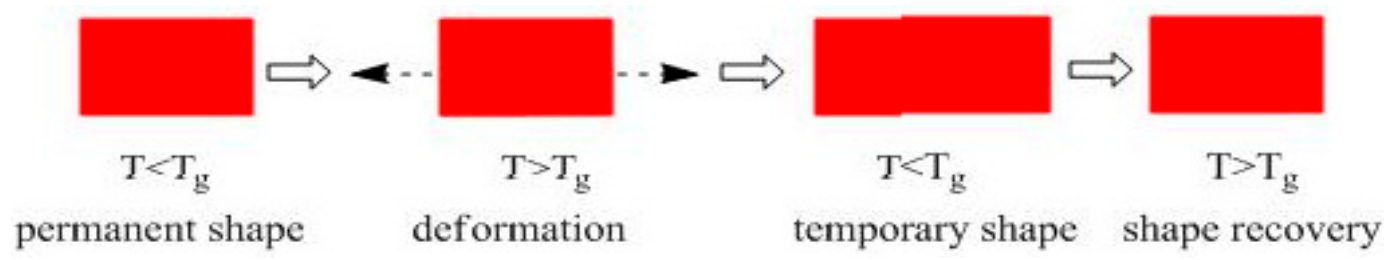

Figure 2. Physical process of shape recovery for a thermo-sensible material with memory shape.

Acknowledgments: The research is being supported by UEFISCDI-grants No. PN.19.23.02.04 and No. 3PS/28.08.2019.

\section{References}

1. Future Trends. Available online: http://matse1.matse.illinois.edu/polymers/future.html (accessed on 20 September 2019).

2. Kupper, D.; Heising, W.; Corman, G.; Wolfgang, M.; Knizek, C.; Lukik, V. Get Ready for Industrialized Additive $\quad 2017.2$ Avanufacturing. online: https://www.bcg.com/publications/2017/lean-manufacturing-industry-4.0-get-ready-for-industrialized-ad ditive-manufacturing.aspx (accessed on 20 September 2019).

(C) 2019 by the authors. Licensee MDPI, Basel, Switzerland. This article is an open access article distributed under the terms and conditions of the Creative Commons Attribution (CC BY) license (http://creativecommons.org/licenses/by/4.0/). 